\title{
Correlates of perceived HIV-related stigma among HIV- positive pregnant women in rural Mpumalanga province, South Africa
}

Citation for published version (APA):

Ramlagan, S., Sifunda, S., Peltzer, K., Jean, J., \& Ruiter, R. A. C. (2019). Correlates of perceived HIVrelated stigma among HIV-positive pregnant women in rural Mpumalanga province, South Africa. Journal of Psychology in Africa, 29(2), 141-148. https://doi.org/10.1080/14330237.2019.1603022

Document status and date:

Published: 04/03/2019

DOI:

10.1080/14330237.2019.1603022

Document Version:

Publisher's PDF, also known as Version of record

Document license:

Taverne

Please check the document version of this publication:

- A submitted manuscript is the version of the article upon submission and before peer-review. There can be important differences between the submitted version and the official published version of record.

People interested in the research are advised to contact the author for the final version of the publication, or visit the DOI to the publisher's website.

- The final author version and the galley proof are versions of the publication after peer review.

- The final published version features the final layout of the paper including the volume, issue and page numbers.

Link to publication

\footnotetext{
General rights rights.

- You may freely distribute the URL identifying the publication in the public portal. please follow below link for the End User Agreement:

www.umlib.nl/taverne-license

Take down policy

If you believe that this document breaches copyright please contact us at:

repository@maastrichtuniversity.nl

providing details and we will investigate your claim.
}

Copyright and moral rights for the publications made accessible in the public portal are retained by the authors and/or other copyright owners and it is a condition of accessing publications that users recognise and abide by the legal requirements associated with these

- Users may download and print one copy of any publication from the public portal for the purpose of private study or research.

- You may not further distribute the material or use it for any profit-making activity or commercial gain

If the publication is distributed under the terms of Article $25 \mathrm{fa}$ of the Dutch Copyright Act, indicated by the "Taverne" license above, 
See discussions, stats, and author profiles for this publication at: https://www.researchgate.net/publication/332888752

\section{Correlates of perceived HIV-related stigma among HIV-positive pregnant women in rural Mpumalanga province, South Africa}

Article in Journal of Psychology in Africa · March 2019

DOI: 10.1080/14330237.2019.1603022

\section{CITATIONS}

3

5 authors, including:

Sibusiso Sifunda

Human Sciences Research Council (HSRC)

76 PUBLICATIONS 722 CITATIONS

SEE PROFILE

Jenny Jean

University of Rochester Medical Center

4 PUBLICATIONS 26 CITATIONS

SEE PROFILE
12. Karl Peltzer

Human Sciences Research Council (HSRC) 922 PUBLICATIONS 18,447 CITATIONS

SEE PROFILE

Robert A C Ruiter

Maastricht University

300 PUBLICATIONS 9,542 CITATIONS

SEE PROFILE

Some of the authors of this publication are also working on these related projects:

Project TCAM among patients with chronic diseases in Sub-Mekong region View project

Project Physical inactivity and associated factors among university students View project 


\section{Correlates of perceived HIV-related stigma among HIV-positive pregnant women in rural Mpumalanga province, South Africa}

Shandir Ramlagan, Sibusiso Sifunda, Karl Peltzer, Jenny Jean \& Robert A.C. Ruiter

To cite this article: Shandir Ramlagan, Sibusiso Sifunda, Karl Peltzer, Jenny Jean \& Robert A.C. Ruiter (2019) Correlates of perceived HIV-related stigma among HIV-positive pregnant women in rural Mpumalanga province, South Africa, Journal of Psychology in Africa, 29:2, 141-148

To link to this article: https://doi.org/10.1080/14330237.2019.1603022

曲 Published online: 05 May 2019.

Submit your article to this journal

View Crossmark data $₫$ 


\title{
Correlates of perceived HIV-related stigma among HIV-positive pregnant women in rural Mpumalanga province, South Africa
}

\author{
Shandir Ramlagan ${ }^{1,2, *(D)}$, Sibusiso Sifunda ${ }^{1,2}$ (i), Karl Peltzer ${ }^{1,3}$ (iD) Jenny Jean ${ }^{4}$ and Robert A.C. Ruiter ${ }^{2}$ (D) \\ ${ }^{1}$ HIV/Aids, STI and TB Unit, Human Sciences Research Council, Pretoria, South Africa \\ ${ }^{2}$ Department of Work and Social Psychology, Maastricht University, Maastricht, The Netherlands \\ ${ }^{3}$ Department of Research and Innovation, University of Limpopo, Sovenga, South Africa \\ ${ }^{4}$ Miller School of Medicine, University of Miami, Miami, USA \\ *Corresponding author email: sramlagan@hsrc.ac.za
}

\begin{abstract}
The study investigated correlates of perceived HIV-related stigma among 673 HIV-positive women from rural Mpumalanga province, South Africa (mean age 28 years old, $\mathrm{SD}=5.73$ years). The women completed measures of HIV-related stigma experience and related personal factors. Following multivariable logistic regression, results showed that lack of male involvement during the ante-natal visits was significantly associated with all four perceived HIV-related stigma factors. Lower income, intimate partner violence (IPV), lower education, and experienced HIV-related stigma were associated with a combination of the four components of perceived HIV-related stigma. From these findings, we conclude that higher levels of education, income, and partner involvement are protective factors against perceived HIV-related stigma, at multiple layers. Improving on adult education and income generating activities can help in reducing HIV-related stigma. Male partner involvement in their partner's pregnancy, the initiation of support groups for both women and men, as well as community-based IPV prevention interventions may help to reduce perceived HIV-related stigma among women living with HIV.
\end{abstract}

Keywords: HIV, negative self-image, pregnant, stigma, women

\section{Introduction}

Stigma has been defined as the possession of a devalued trait, behaviour, or identity that results in the reduced status of individuals that possesses that trait, behaviour, or identity (Bos et al., 2013; Brown et al., 2003; Hasan et al., 2012; Tsai et al., 2013). Women living with HIV are particularly vulnerable (Bell et al., 2007; Campbell et al., 2006; Lekas et al., 2006; Matseke et al., 2016; Mwaura, 2008; Rankin et al, 2005; Yuh et al, 2014; Sangaramoorthy et al., 2017); especially those from low resource countries (Avert, 2018; Bos et al., 2008; Magadi, 2011; Mwaura, 2008; Tsai et al., 2015). Women's vulnerability to stigma is multifactorial and at its core compounded by their gendered positionality in society and the "volitional acquirability" of HIV (Carr and Gramling 2004; Earnshaw et al. 2013, 2015; Sangaramoorthy et al., 2017). The disruptiveness of HIV-related stigma on women's interpersonal relationships potentiates their vulnerability (Crandall \& Moriarty, 1995).

Stigma operates at three levels: enacted, anticipated, and internalised. Enacted stigma refers to individuals' experience of current or past stereotyping, prejudiced, and stigmatising behaviours such as discrimination or exclusion due to their possession of the devalued trait (Bos et al., 2013; Earnshaw et al., 2013; Mbonye et al., 2013). Anticipated stigma is the expectation of future experiences of prejudice, stigmatising behaviours, and stereotyping due to one's possession of the devalued attribute (Earnshaw et al., 2013). Internalised stigma is defined as individuals' acceptance of the social construction of their attributes, behaviour, or identity as undesirable and the ensuing reduction in status as legitimate (Earnshaw et al., 2013; Rao et al., 2012). Inherent to internalised stigma is the development of self-depreciating constructions of oneself through the embodiment of shame, guilt, blame, and hopelessness (Brown et al., 2003; Earnshaw et al., 2013; Rao et al., 2012). Internalised HIV-related stigma is HIV-positive individuals' acceptance and subsequent identification of their selves with the negative or devalued construction of what it means to be an HIV-positive person (Kingori et al., 2012; Rao et al., 2012).

Women living with HIV are vulnerable to enacted, anticipated, and internalised stigma (Campbell et al., 2006; Makin et al., 2010; Sangaramoorthy et al., 2017). Women in sub-Saharan Africa account for the majority of the HIV/ AIDS burden in the region. As such, they are confronted with perceived HIV-related stigma at much higher rates than men (Magadi, 2011; Mwaura, 2008). The available literature on stigma among HIV-positive individuals demonstrates higher rates of stigma among HIV-positive individuals when compared to the larger community and variability in the gendered prevalence of such stigma (Kako et al., 2013; Kalichman et al., 2005; Simbayi et al., 2007). Simbayi and colleagues (2007) demonstrated that men experienced higher rates of reported stigma compared to women. However, although depression was positively correlated with stigma, women experienced higher rates of depression than men (Simbayi et al., 2007). In contrast, Mugoya and colleagues (2014) found that when compared to their male counterparts, HIV-positive women were more likely to endorse higher rates of stigma and to experience more severe levels of stigma.

One mode through which HIV-positive women are more vulnerable to stigma and the internalisation of stigma, is through the idea of intersectionality (Carr \& Gramling 2004; Earnshaw et al., 2013). Some of the literature postulates and demonstrates that an HIV diagnosis compounds the societal inequities and associated 
stigma already tied to their raced, classed, and gendered identities (Kako \& Dubrosky, 2013; Lekas et al., 2006; Mwaura, 2008; Sandelowski et al., 2004; Sangaramoorthy et al., 2017). Campbell and colleagues (2006) note three main driving forces of maintaining stigma among women: (i) fear of being infected with HIV in the setting of high rates of infections, (ii) poverty, and (iii) stigmatisation of sexuality, particularly women's sexuality. Consequently, women's particular vulnerability to HIV-related stigma is mediated by the discourse around notions of who gets infected with HIV and the idea that women's acquirement of HIV is a result of behaviours of "immoral" womanhood such as promiscuity and/or intravenous drug use (Lekas et al., 2006; Sangaramoorthy et al., 2017). Additionally, at the intersection of womanhood and poverty, HIV-positive women's vulnerability to experiencing stigma is shaped by societal disapproval of mothering in context of poverty and/or risk of transmitting HIV to a child (Sandelowski et al., 2004). According to Sangaramoorthy and colleagues (2017), HIV-positive women revealed a sense of shame around having their decisions for motherhood in the context of disclosed HIV being framed as immoral.

HIV-related stigma among HIV-positive women has been shown to be tied to lower rates of disclosure and lower engagement in HIV-related care (Crandall \& Moriarty, 1995; Makin et al., 2010; Medley et al., 2004; Ramlagan et al., 2018; Sangaramoorthy et al., 2017). Although numerous studies have demonstrated the modes in which HIV-positive women are vulnerable to experiencing stigma and the association with negative health outcomes, there remains a gap in our knowledge of how stigma is experienced by HIV-positive pregnant women and factors that predict the level and type of stigma they experience (Sangaramoorthy et al., 2017; Sandelowski et al., 2009). This knowledge gap is particularly apparent for those who are pregnant and living in resource-limited communities (Sangaramoorthy et al., 2017; Sandelowski et al., 2009).

\section{Significance of the study}

Characterising stigma operating at the perceived level is of particular importance not only for the ways HIV-related stigma impacts on the health of People Living with HIV (PLHIV), but also because, as demonstrated within a South African context, the general adult population harbours less negative views about HIV when compared to the perceived stigma experienced by PLHIV (Kalichman et al., 2005; Simbayi et al., 2007). HIV-related stigma has been linked to greater determent from seeking HIV-related treatment, avoidance of prevention of mother to child transmission (PMTCT) programs, and decreased rates of disclosure (Kingori et al., 2012; Rahangdale et al., 2010; Tsai et al., 2013).

\section{Goal of the study}

This study aimed to examine HIV-related correlates of perceived HIV-related stigma among HIV-positive pregnant women in rural Mpumalanga province, South Africa. It sought to address the following questions:

- What are the personal characteristics and HIV factors that predict experience of perceived HIV-related stigma?
- What are the roles of intimate partner violence (IPV) and male involvement in the experience of perceived HIV-related stigma?

- How are levels of depressive symptoms related to perceived HIV-related stigma?

\section{Method \\ Study design and population}

This study is part of the larger Protect Your Family (PYF) randomised controlled trial conducted among HIVpositive, less than six months pregnant, black African women, attending 12 community health centres (CHCs) in Nkangala and Gert Sibande districts in Mpumalanga province, South Africa (Jones et al., 2014). The crosssectional data we report on were gathered between April 2014 and March 2015.

\section{Participants and setting}

A total of 673 HIV-positive pregnant women were participants (mean age $=28$ years, $\mathrm{SD}=5.73$ years). Sample demographics are presented in Table 1. The majority (71.5\%) did not complete grade 12 (matric) schooling. A high third of the participants reported that their monthly household income was less than R310 which was the South African government child grant amount during the study time period. Off all respondents, $20 \%$ stated that they experienced mild to severe physical violence from their intimate partners, $41 \%$ experienced AIDS related stigma, and $42 \%$ experienced no male partner involvement during this pregnancy (see Table 1). Interestingly, half of the HIV-positive pregnant women experienced low depression and just over half were diagnosed as HIV-positive during this pregnancy.

\section{Measures}

Participants completed the following measures: Perceived HIV Stigma Scale (PHSS: Berger et al., 2001; Lindberg et al., 2014); HIV Treatment Management Measures (Diagnosis); antiretroviral (ARV) adherence using the Visual Analogue Scale (VAS; Giordano et al., 2004); IPV using the Conflict Tactics Scale (CTS: Straus, 1979); the AIDS-Related Stigma Scale (ARSS: Kalichman et al., 2005); and depression using the Edinburgh Postnatal Depression Scale 10 (EPDS-10: Cox et al., 1987). Furthermore, they self-reported their demographics including age at last birthday, educational attainment, relationship status, employment status, income per month in South African Rand (ZAR), number of children, if this pregnancy was unplanned, and alcohol usage of more than two drinks on at least one occasion in the previous four weeks.

\section{The Perceived HIV Stigma Scale}

The PHSS is a 40-items measure of stigma as perceived by people with HIV (Berger et al., 2001; Lindberg et al., 2014). Items were answered on a 4-point Likert-scale ranging from strongly disagree, to strongly agree. Example statements of the scale include: "Having HIV makes me feel unclean"; "I regret having told some people that I have HIV"; and "Having HIV in my body is disgusting to 
Table 1. Sample demographics

\begin{tabular}{|c|c|}
\hline Variable & $n(\%)$ \\
\hline$\overline{\text { All }}$ & $673(100)$ \\
\hline \multicolumn{2}{|l|}{ Age $($ mean $=28.39, \mathrm{SD}=5.73)$} \\
\hline \multicolumn{2}{|l|}{ Educational attainment } \\
\hline Grade 12 or more & $192(28.5)$ \\
\hline Grade 11 and less & 481(71.5) \\
\hline \multicolumn{2}{|l|}{ Relationship status } \\
\hline Not living together & $419(62.3)$ \\
\hline Living together & $254(37.7)$ \\
\hline \multicolumn{2}{|l|}{ Employment status } \\
\hline Not employed & $527(78.3)$ \\
\hline Employed, volunteer or student & $146(21.7)$ \\
\hline \multicolumn{2}{|l|}{ Income (ZAR)per month } \\
\hline$<\mathrm{R} 310$ & $221(32.8)$ \\
\hline R311 or more & $452(67.2)$ \\
\hline \multicolumn{2}{|l|}{ Number of children } \\
\hline None & $139(20.7)$ \\
\hline One or more & $534(79.3)$ \\
\hline \multicolumn{2}{|l|}{ Unplanned pregnancy } \\
\hline No & $317(47.1)$ \\
\hline Yes & $356(52.9)$ \\
\hline \multicolumn{2}{|l|}{$\begin{array}{l}\text { Alcohol use of more than } 2 \text { drinks on at } \\
\text { least on one occasion in the past } 4 \text { weeks }\end{array}$} \\
\hline No & $581(86.3)$ \\
\hline Yes & $92(13.7)$ \\
\hline \multicolumn{2}{|l|}{ Diagnosed with HIV in this pregnancy } \\
\hline No, before & $308(45.8)$ \\
\hline Yes & $365(54.2)$ \\
\hline \multicolumn{2}{|l|}{ Has HIV-positive children } \\
\hline No or do not know & $506(75.2)$ \\
\hline Yes & $28(4.2)$ \\
\hline \multicolumn{2}{|l|}{ VAS adherence } \\
\hline Non adherent & $210(31.2)$ \\
\hline $100 \%$ adherent & $463(68.8)$ \\
\hline \multicolumn{2}{|l|}{ HIV-positive partner } \\
\hline No or do not know & $506(75.2)$ \\
\hline Yes & $167(24.8)$ \\
\hline \multicolumn{2}{|l|}{ Intimate partner violence } \\
\hline No mild or No severe physical violence & $541(80.4)$ \\
\hline Mild or severe physical violence & $132(19.6)$ \\
\hline \multicolumn{2}{|l|}{ AIDS related stigma } \\
\hline No & $400(59.4)$ \\
\hline Yes & $273(40.6)$ \\
\hline \multicolumn{2}{|l|}{ Depression } \\
\hline No/Low & $345(51.3)$ \\
\hline High & $328(48.7)$ \\
\hline \multicolumn{2}{|l|}{ Male involvement } \\
\hline No & 281(41.8) \\
\hline Yes & $392(58.2)$ \\
\hline
\end{tabular}

me." In the present study, Cronbach's Alpha reliability for scores from the PHSS was $\alpha=0.96$.

\section{HIV treatment management}

HIV treatment management related questions included whether the HIV diagnosis was made during their current pregnancy; whether the participant has any HIVpositive children; and partners' HIV status. Furthermore, male involvement (in other words, whether their male partner knew what occurred during in the antenatal clinic visit) was also captured. This was assessed using one question: "Does your male partner know what happens in the antenatal clinic?" Response to the question was dichotomous, i.e. Yes/No.

\section{ARV adherence measure with the VAS}

ARV adherence was assessed using the seven day recall VAS (Giordano et al., 2004) where participants were recorded as "adherent" (coded 1) if they took all their medication on all seven days, and as " 0 " if they missed any of their medication during the past seven days (Ramlagan et al., 2018).

\section{IPV measured with the CTS}

IPV was assessed utilising the 18-item CTS (CTS-18: Straus, 1979). A higher score on the scale is indicative of increased IPV. For the present study, Cronbach's Alpha reliability for scores from the CST-18 was $\alpha=0.84$.

\section{AIDS-Related Stigma Scale}

The ARSS is a 9-item measure of internal representations of AIDS-related stigma (Kalichman et al., 2005). Scores on the scale range from 0 to 8 , where higher scores indicate greater levels of stigma. In the present study, Cronbach's Alpha reliability for scores from the ARSS was $\alpha=0.73$.

\section{Depression measured with the EPDS-10}

Depression was assessed utilising the EPDS-10, a 10-item measure of depression (Cox et al., 1987). Scores ranged from 0 to 30 , where the higher the score, the more the likelihood of depression. The validated cut-off score of 12 for South African populations was utilised (Lawrie, 1998). In the present study, Cronbach's Alpha reliability for scores from the EPDS-10 was $\alpha=0.66$.

\section{Procedure}

Ethical approval was granted by the University of Miami Miller School of Medicine Institutional Review Board (IRB ID: 20130238 (CR00006122)) as well as the South African Human Sciences Research Council Research Ethics Committee with Protocol No REC 4/21/08/13. As the study was being conducted in Mpumalanga Province, study approval was also obtained from the Mpumalanga Provincial Government, Department of Health.

Participants were only included if they were 18 years or older, were HIV-positive, were less than six months pregnant, not part of the PYF study at another study site, having a partner (not necessarily the father of the foetus), and willing to participate in this study. Once consented, participants completed the interview on Audio ComputerAssisted Self-Interview (ACASI) technology (NIMH Multisite HIV/STD Prevention Trial for African American Couples Group, 2008).

Interviews were conducted either in English, seSotho, or isiZulu. The written questionnaire was first translated into seSotho and isiZulu and then independently backtranslated. The approved translations were then audio recorded by two female project researchers who could converse in the languages. The audio and written 
questionnaires were synced and uploaded onto laptops, at which time the study field staff tested them for accuracy. For completing the baseline interview, participants were given R50.00 (South African Rands) or US\$4.72.

\section{Data analysis}

Software SPSS, version 24.0 (IBM Corp, 2016) was used for data analyses. Univariate and multivariable logistic regression were used to investigate associations between the four factors of perceived HIV-related stigma and socioeconomic, HIV-related, and behavioural variables. Associations were considered significant at $p<0.05$. All statistically significant variables in the univariate analyses were included in the multivariable logistic regression. Multi-collinearity was tested.

\section{Results}

Table 2 and Table 3 present the correlations and reliability indices for the perceived HIV-related stigma measures. As indicated in table 3, in the present study, Cronbach's Alpha reliability scores for each of the four subscales ranged between $\alpha=0.79$ and $\alpha=0.94$; providing evidence for the internal consistency of the resulting subscales.

Table 4 presents the findings from the univariate and multivariable logistic regression predicting HIV-related stigma from personal factors and HIV variables. These predictions suggest that those with lower education and income, who experience IPV, and those with no male involvement in their current pregnancy, were more likely to experience personalised stigma.

As indicated in Table 4, both univariate and multivariable logistic regression found that those with a lower income and those with no male involvement in their current pregnancy were more likely to experience concerns with public attitude and have disclosure concerns. A negative self-image was predicted by those who experienced more HIV-related stigma and those with no male involvement in their current pregnancy.

\section{Discussion}

This study sought to predict correlates of perceived HIVrelated stigma among HIV-positive pregnant women in a South African rural community.

Having no male partner involvement in the pregnancy was significantly associated with experiencing all four of the HIV-related stigma factors. This significant finding leads us to deduce that positive male involvement seems critical in assisting pregnant women to potentially reduce what Scheff (1966) defines as their self-defacing beliefs and perceptions of themselves. Male involvement in PMTCT has been recognised as a priority area in the elimination of mother-to-child transmission of HIV where their positive involvement in the pregnancy can have an influence in the extended social environment of the family, can increase health seeking behaviour, can increase adherence to ARV medication as well as clinic appointments, and assist to mitigate stigma (WHO, 2012). It is imperative to caution that, in this study, male involvement was measured by utilising only one question. Using one question as a measure of involvement in pregnancy is limiting and as such, the result, although significant must be interpreted with caution as additional in-depth research in the area of male involvement in reducing stigma among HIV-positive women is needed.

Women with a low income were more likely to experience three of the four HIV-related stigma factors. This finding is similar to the finding of Tsai and colleagues (2015), who noted that PLHIV from poorer households were at more than twice the risk of experiencing HIVrelated stigma. Additionally, poverty is one of the three main driving forces of maintaining stigma (Campbell et al., 2006). Poverty increases vulnerability (Avert, 2018). Furthermore, Matseke and colleagues (2016) found that poverty combined with HIV-positive status leads to additional burden in the lives of pregnant women. This burden places HIV-positive, stigmatised women at risk of being less able to adopt HIV risk-reducing behaviours

Table 2. Correlation matrix and variance of the four dimensions of perceived HIV-related stigma

\begin{tabular}{|c|c|c|c|c|c|}
\hline & & 1 & 2 & 3 & 4 \\
\hline 1 & Personalised stigma & 1 & & & \\
\hline 2 & Concerns with public attitude & $0.489^{* *}$ & 1 & & \\
\hline 3 & Disclosure concerns & $0.676^{* *}$ & $0.524^{* *}$ & 1 & \\
\hline 4 & Negative self-image & $0.699^{* *}$ & $0.628^{* *}$ & $0.682^{* *}$ & 1 \\
\hline \multicolumn{2}{|c|}{ Eigenvalues } & 15.53 & 2.87 & 1.63 & 1.45 \\
\hline \multicolumn{2}{|c|}{$\%$ variance } & 38.81 & 7.17 & 4.08 & 3.63 \\
\hline \multicolumn{2}{|c|}{$N$} & 673 & 673 & 673 & 673 \\
\hline
\end{tabular}

Note. $* *$ Correlation is significant at the 0.01 level (2-tailed)

Table 3. Descriptive of the four perceived HIV-related stigma factors $(N=673)$

\begin{tabular}{lccccc}
\hline Factor name & Items & M(SD) & Skewness* & Kurtosis** & Alpha \\
\hline Personalised stigma & 17 & $35.17(10.38)$ & 0.209 & 0.005 & 0.944 \\
Concerns with public attitude & 7 & $15.98(4.56)$ & 0.140 & -0.077 & 0.794 \\
Disclosure concerns & 6 & $14.36(4.00)$ & -0.219 & 0.007 & 0.015 \\
Negative self-image & 10 & $21.14(6.54)$ & 0.316 & 0.894 \\
\hline
\end{tabular}

Note. $*$ Std Error $=0.094 ; * *$ Std Error $=0.188$ 
Antenatal HIV-related stigma

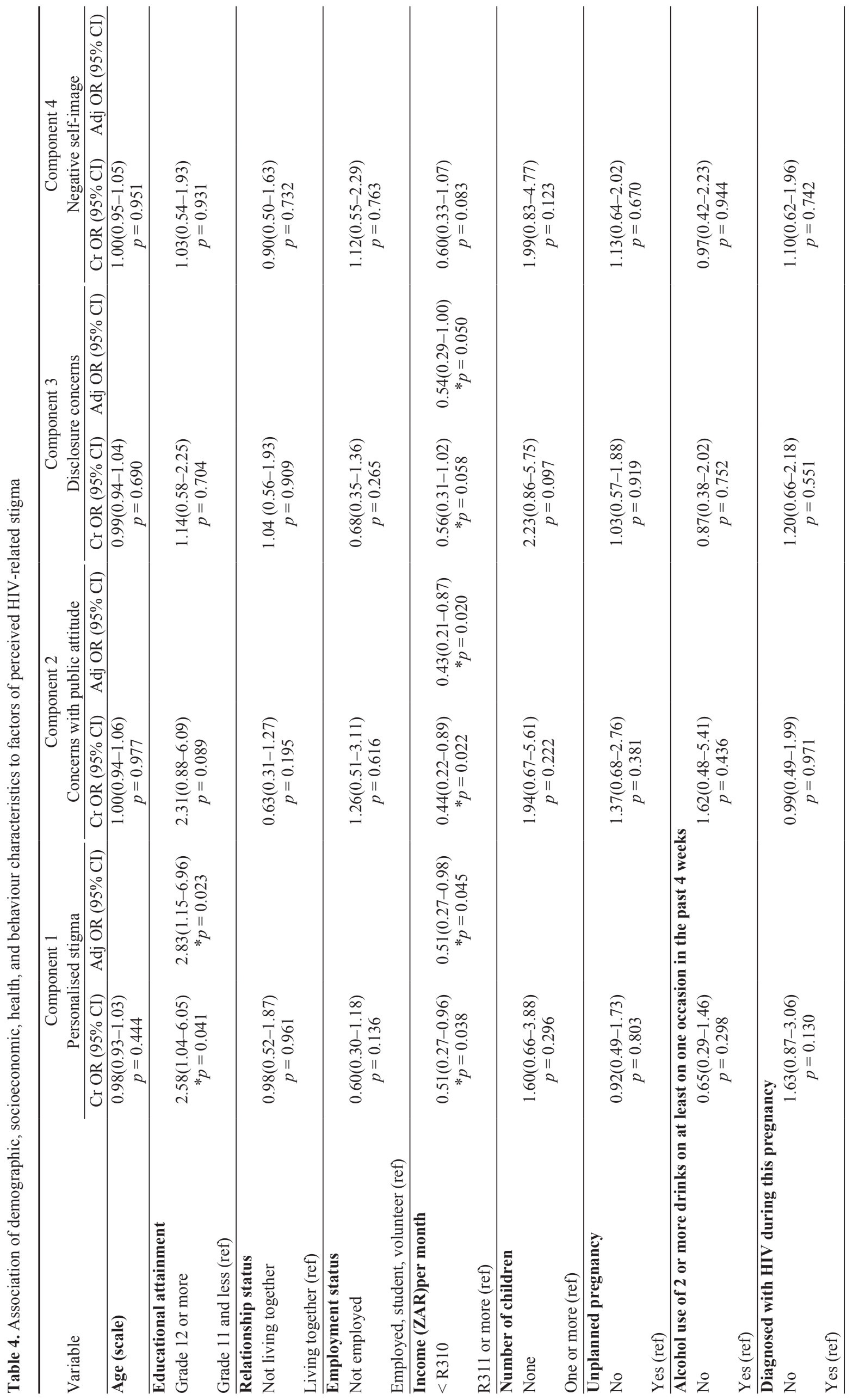




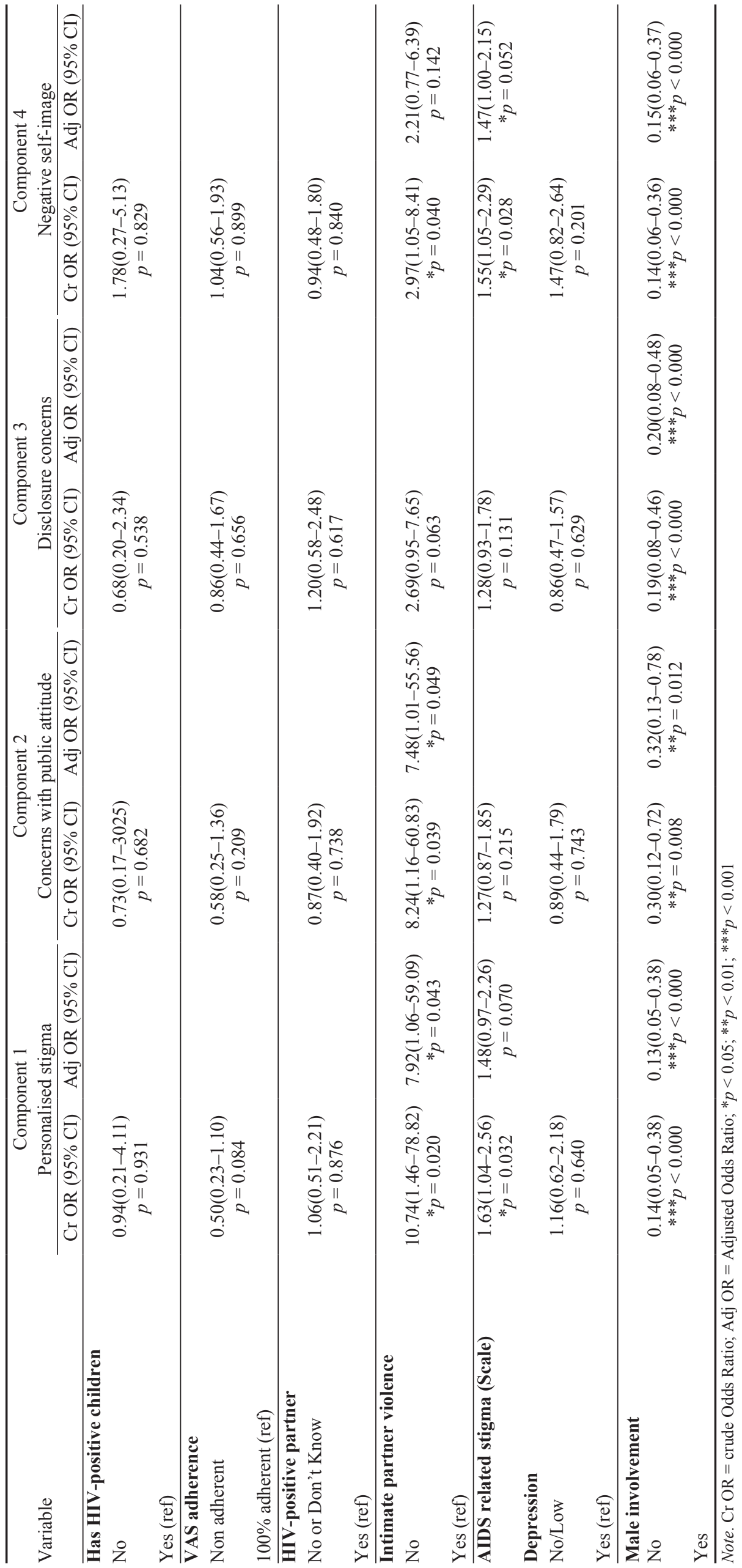


(Avert, 2018) and thus perpetuating the cycle of their devalued perceptions of themselves.

IPV was significantly associated with experiencing personalised stigma. This might be explained by the fact that experiencing IPV while HIV-positive and pregnant can lead to the development of self-deprecating constructions of oneself through the embodiment of shame, guilt, blame, and hopelessness (Brown et al., 2003; Earnshaw et al., 2013; Rao et al., 2012). It is this acceptance and subsequent identification with the devalued construction of themselves (Kingori et al., 2012; Rao et al., 2012) that probably leads to increased perceived HIV-related stigma. This could also be related to ARSS related stigma, which was experienced by an extremely high $41 \%$ of the study population, and was only associated in the multivariable logistic regression with the stigma of negative self-image.

Participants that did not complete school, were more likely to experience personalised stigma. This finding is similar to that of Sekoni, Obidike, and Balogun (2012) who found association between higher education and lower levels of personalised and disclosure stigma. As with IPV mentioned above, those with a lower education may also develop self-deprecating constructions of themselves (Brown et al., 2003; Earnshaw et al., 2013; Rao et al., 2012). This could be due to those with lower levels of education also experiencing poorer living and working conditions (Sekoni et al., 2012). Additionally, they may be less knowledgeable about adopting risk-reducing behaviours (Avert, 2018).

\section{Conclusion}

In conclusion, this study reveals the ways in which higher levels of education, income, and positive partner involvement (outside of the context of IPV) serve as protective factors against perceived HIV-related stigma, at multiple layers. Improving on adult education and income generating activities can help in reducing HIVrelated stigma. Strategies need to be developed to encourage male partners to be positively involved in their partner's pregnancy and as such, more research is required to explore male involvement in PMTCT in the South African context. Immediate action is needed to tackle IPV and could be achieved through community-based IPV prevention interventions and support groups for both women and men.

\section{Authors' note \\ The authors declare that they have no competing interests. The funding sponsors had no role in the design of the study; in the collection, analyses, nor interpretation of data; in the writing of the manuscript; nor the decision to publish the results. Funding for the study was received from the National Institutes of Health with grant number R01HD078187. Trial registration: ClinicalTrials.gov NCT02085356 (registration date: 10 March 2014).}

\section{ORCID}

Shandir Ramlagan iD http://orcid.org/0000-0001-9906-4474 Sibusiso Sifunda iD http://orcid.org/0000-0002-8766-7240 Karl Peltzer iD http://orcid.org/0000-0002-5980-0876

Robert A.C. Ruiter (iD http://orcid.org/0000-0001-5017-3258

\section{References}

Avert. (2018). Women and Girls, HIV and AIDS. Available from: https://www.avert.org/professionals/hiv-social-issues/ key-affected-populations/women. Retrieved 04 March 2019.

Bell, E., Mthembu, P., O’Sullivan, S., \& Moody, K. (2007). Sexual and reproductive health services and HIV testing: Perspectives and experiences of women and men living with HIV and AIDS. Reproductive Health Matters, 15(29 Suppl), 113-135. https://doi.org/10.1016/S0968-8080(07)29029-9

Berger, B. E., Ferrans, C. E., \& Lashley, F. R. (2001). Measuring stigma in people with HIV: Psychometric assessment of the HIV stigma scale. Research in Nursing \& Health, 24(6), 518-529. https://doi.org/10.1002/nur.10011

Bos, A. E. R., Pryor, J. B., Reeder, G. D., \& Stutterheim, S. E. (2013). Stigma: Advances in theory and research. Basic and Applied Social Psychology, 35(1), 1-9. https://doi.org/10.10 80/01973533.2012.746147

Bos, A. E. R., Schaalma, H. P., \& Pryor, J. B. (2008). Reducing AIDS-related stigma in developing countries: The importance of theory- and evidence-based interventions. Psychology Health and Medicine, 13(4), 450-460. https:// doi.org/10.1080/13548500701687171

Brown, L., Macintyre, K., \& Trujillo, L. (2003). Interventions to reduce HIV/AIDS stigma: What have we learned? AIDS Education and Prevention, 15(1), 49-69. https://doi. org/10.1521/aeap.15.1.49.23844

Campbell, C., Nair, Y., \& Maimane, S. (2006). AIDS stigma, sexual moralities and the policing of women and youth in South Africa. Feminist Review, 83(1), 132-138. https://doi. org/10.1057/palgrave.fr.9400285

Carr, R. L., \& Gramling, L. F. (2004). Stigma: A health barrier for women with HIV/AIDS. The Journal of the Association of Nurses in AIDS Care, 15(5), 30-39. https://doi. org/10.1177/1055329003261981

Corp, I. B. M. (2016). IBM SPSS Statistics for Windows, Version 24.0. Armonk, NY: IBM Corp.

Cox, J., Holden, J., \& Sagovsky, R. (1987). Detection of postnatal depression: Development of the 10-item Edinburgh Postnatal Depression Scale. The British Journal of Psychiatry, 150(6), 782-786. https://doi.org/10.1192/bjp.150.6.782

Crandall, C. S., \& Moriarty, D. (1995). Physical illness stigma and social rejection. British Journal of Social Psychology, 34(1), 67-83. https://doi.org/10.1111/j.2044-8309.1995. tb01049.x

Earnshaw, V. A., Bogart, L. M., Dovidio, J. F., \& Williams, D. R. (2015). Stigma and racial/ethnic HIV disparities: moving toward resilience. American Psychologist, 68(4), 225-236. https://www.ncbi.nlm.nih.gov/pmc/articles/PMC3740715/

Earnshaw, V. A., Smith, L. R., Chaudoir, S. R., Amico, K. R., \& Copenhaver, M. M. (2013). HIV stigma mechanisms and well-being among PLWH: A test of the HIV stigma framework. AIDS and Behavior, 17(5), 1785-1795. https:// doi.org/10.1007/s10461-013-0437-9

Giordano, T. P., Guzman, D., Clark, R., Charlebois, E. D., \& Bangsberg, D. R. (2004). Measuring adherence to antiretroviral therapy in a diverse population using a visual analogue scale. HIV Clinical Trials, 5(2), 74-79. https://doi. org/10.1310/JFXH-G3X2-EYM6-D6UG

Hasan, M. T., Nath, S. R., Khan, N. S., Akram, O., Gomes, T. M., \& Rashid, S. F. (2012). Internalized HIV/AIDS-related stigma in a sample of HIV-positive people in Bangladesh. Journal of Health, Population and Nutrition, 30(1), 22-30. https://doi.org/10.3329/jhpn.v30i1.11272

Kako, P.M., \& Dubrosky, R. (2013). "You comfort yourself and believe in yourself": Exploring lived experiences of stigma in HIV-positive Kenyan women. Issues in Mental Health Nursing, 34(3), 150-157. https://doi.org/10.3109/01612840 .2012 .740765 
Jones, D., Peltzer, K., Weiss, S. M., Sifunda, S., Dwane, N., Ramlagan, S., . . . Spence, A. (2014). Implementing comprehensive prevention of mother-to-child transmission and HIV prevention for South African couples: Study protocol for a randomized controlled trial. Trials, 15(417), 1-9. https://doi.org/10.1186/1745-6215-15-417

Kalichman, S. C., Simbayi, L. C., Jooste, S., Toefy, Y., Cain, D., Cherry, C., \& Kagee, A. (2005). Development of a brief scale to measure AIDS-related stigma in South Africa. AIDS and Behavior, 9(2), 135-143. https://doi.org/10.1007/ s10461-005-3895-x

Kingori, C., Reece, M., Obeng, S., Murray, M., Shacham, E., Dodge, B., . . . Ojakaa, D. (2012). Impact of internalised stigma on HIV prevention behaviors among HIV-infected individuals seeking HIV care in Kenya. AIDS Patient Care and STDs, 26(12), 761-768. https://doi.org/10.1089/ apc. 2012.0258

Lawrie, T. A., Hofmeyr, G. J., De Jager, M., \& Berk, M. (1998). Validation of the Edinburgh Postnatal Depression Scale on a cohort of South African women. South African Medical Journal, 88(10), 1340-1344.

Lekas, H. M., Siegel, K., \& Schrimshaw, E. W. (2006). Continuities and discontinuities in the experiences of felt and enacted stigma among women with HIV/AIDS. Qualitative Health Research, 16(9), 1165-1190. https://doi. org/10.1177/1049732306292284

Lindberg, M. H., Wettergren, L., Wiklander, M., SvedhemJohansson, V., \& Eriksson, L. E. (2014). Psychometric evaluation of the HIV Stigma Scale in a Swedish context. PLoS One, 9(12), e114867. https://doi.org/10.1371/journal. pone. 0114867

Magadi, M. A. (2011). Understanding the gender disparity in HIV infection across countries in sub-Saharan Africa: Evidence from the Demographic and Health Surveys. Sociology of Health \& Illness, 33(4), 522-539. https://doi. org/10.1111/j.1467-9566.2010.01304.x

Makin, J. D., Forsyth, B. W., Visser, M. J., Sikkema, K. J., Neufeld, S., \& Jeffery, B. (2008). Factors affecting disclosure in South African HIV-positive pregnant women. AIDS Patient Care and STDs, 22(11), 907-916. https://doi. org/10.1089/apc.2007.0194

Matseke, G., Rodriguez, V. J., Peltzer, K., \& Jones, D. (2016). Intimate partner violence among HIV-positive pregnant women in South Africa. Journal of Psychology in Africa, 26(3), 259-266. https://doi.org/10.1080/14330237.2016.11 85912

Mbonye, M., Nakamanya, S., Birungi, J., King, R., Seeley, J., \& Jaffar, S. (2013). Stigma trajectories among people living with HIV (PLHIV) embarking on a life time journey with antiretroviral drugs in Jinja, Uganda. BMC Public Health, 13(804), 1-11. https://doi.org/10.1186/1471-2458-13-804

Medley, A., Garcia-Moreno, C., McGill, S., \& Maman, S. (2004). Rates, barriers and outcomes of HIV serostatus disclosure among women in developing countries: Implications for prevention of mother-to-child transmission programmes. Bulletin of the World Health Organization, 82, 299-307.

Mugoya, G. C., \& Ernst, K. (2014). Gender differences in HIV-related stigma in Kenya. AIDS Care, 26(2), 206-213. https://doi.org/10.1080/09540121.2013.808733

Mwaura, P. N. (2008). Stigmatisation and discrimination of HIV/ AIDS women in Kenya: A violation of human rights and its theological implications. Exchange, 37(1), 35-51. https://doi. org/10.1163/157254308X251322

NIMH Multisite HIV/STD Prevention Trial for African American Couples Group. (2008). Designing an audio computerassisted self-interview system in a multisite trial: A brief report. Journal of Acquired Immune Deficiency Syndromes, 49(Suppl 1), S52-S58. doi:10.1097/QAI.0b013e318184481a.
Rankin, W. W., Brennan, S., Schell, E., Laviwa, J., \& Rankin, S. H. (2005). The stigma of being HIV-positive in Africa. PLoS Medicine, 2(8), 702-704. https://doi.org/10.1371/journal. pmed.0020247

Ramlagan, S., Peltzer, K., Ruiter, R. A. C., Barylski, N. A. Weiss, S. M., \& Sifunda, S. (2018). Prevalence and factors associated with fixed-dose combination antiretroviral drugs adherence among HIV-positive pregnant women on option B treatment in Mpumalanga Province, South Africa. International Journal of Environmental Research and Public Health, 15(161), 1-12. https://doi.org/10.3390/ ijerph15010161

Rao, D., Desmond, M., Andrasik, M., Rasberry, T., Lambert, N., Cohn, S. E., \& Simoni, J. (2012). Feasibility, acceptability, and preliminary efficacy of the unity workshop: An internalised stigma reduction intervention for African American women living with HIV. AIDS Patient Care and STDs, 26(10), 614-620. https://doi.org/10.1089/ apc.2012.0106

Sandelowski, M., Barroso, J., \& Voils, C. I. (2009). Gender, race/ ethnicity, and social class in research reports on stigma in HIV-positive women. Health Care for Women International, 30(4), 273-288. https://doi.org/10.1080/07399330802694880

Sandelowski, M., Lambe, C., \& Barroso, J. (2004). Stigma in HIV-positive women. Journal of Nursing Scholarship, 36(2), 122-128. https://doi.org/10.1111/j.1547-5069.2004.04024.x

Sangaramoorthy, T., Jamison, A., \& Dyer, T. (2017) Intersectional stigma among midlife and older Black women living with HIV. Culture, Health \& Sexuality, 19(12), 1329-1343. https://doi.org/10.1080/13691058.2017.1312530

Scheff, T. J. (1966). Being mentally ill: a sociological theory. Chicago: Aldine Publishing Co.

Sekoni, A. O., Obidike, O. R., \& Balogun, M. R.(2012). Stigma, medication adherence and coping mechanism among people living with HIV attending General Hospital, Lagos Island, Nigeria. African Journal of Primary Health Care \& Family Medicine, 4(1), 1-10. https://doi.org/10.4102/phcfm. v4i1.417

Simbayi, L. C., Kalichman, S., Strebel, A., Cloete, A., Henda, N., \& Mqeketo, A. (2007). Internalised stigma, discrimination, and depression among men and women living with HIV/ AIDS in Cape Town, South Africa. Social Science \& Medicine, 64(9), 1823-1831. https://doi.org/10.1016/j. socscimed.2007.01.006

Straus, M. A. (1979). Measuring intrafamily conflict and violence: The conflict tactics (CT) scales. Journal of Marriage and the Family, 41(1), 75-88. https://doi.org/10.2307/351733

Tsai, A. C. (2015). Socioeconomic gradients in internalised stigma among 4,314 persons with HIV in sub-Saharan Africa. AIDS and Behavior, 19(2), 270-282. https://doi.org/10.1007/ s10461-014-0993-7

Tsai, A. C., Bangsberg, D. R., Kegeles, S. M., Katz, I. T., Haberer, J. E., Muzoora, C., . . . Weiser, S. D. (2013). Internalised stigma, social distance, and disclosure of HIV seropositivity in rural Uganda. Annals of Behavioral Medicine, 46(3), 285-294. https://doi.org/10.1007/s12160-013-9514-6

Yuh, J. N., Ellwanger, K., Potts, L., \& Ssenyonga, J. (2014). Stigma among HIV/AIDS patients in Africa: A critical review. Procedia: Social and Behavioral Sciences, 140 581-585. https://doi.org/10.1016/j.sbspro.2014.04.474

World Health Organisation. (2012). Male involvement in the prevention of mother-to-child transmission of HIV. Geneva: WHO. 